\section{Structural facilitation in the learning of German} nonsense strings ${ }^{1}$

DANIEL C. O'CONNELL, Saint Louis University, St. Louis, Mo. 63103, and MICHAEL BRAND, Psychological Institute of the Free University of Berlin, 1 Berlin 41, W. Germany

Nonsense strings simulating linguistic structure in German were presented serially to native speakers of German in a 3 by 3 design: structure (none, morphology, morphology and syntax) and rate of presentation. Structural facilitation due to morphology was found but seemed to be modified by a form of subjective organization.

The first study immediately relevant to the present research is Epstein (1962). The research was a replication of an earlier study (Epstein, 1961), in which the author had found facilitation of learning in nonsense strings through the addition of structure. In the second study, serial anticipation was substituted for the whole presentation that had characterized the first study, and the result was a suppression of the structural facilitation. A parallel suppression effect was found in the 1962 study with sententially meaningless (semantically anomalous) word strings.

Wales (1964) was the first to repeat the Epstein (1962) design with anomalous strings. Meaningful sentences were also included in the design. Presentation rates were .8 and $2 \mathrm{sec} / \mathrm{item}$. At the slower rate, significant differences between grammatical and ungrammatical strings for normal and anomalous strings were reduced and disappeared, respectively. Epstein \& Arlinsky (1965) also used semantically anomalous strings. With serial presentation ( $2 \mathrm{sec} / \mathrm{item})$, the superiority of syntactic over unsyntactic material disappeared. The response mode was not serial anticipation but was free recall after serial or whole presentation.

Several other studies that used actual lexical entries have found variant results. Simpson (1965) found that, when Ss learned a list of 30 words by serial anticipation, increasing approximation to sentence word order led to faster learning. Denner (1966) found that serial tachistoscopic presentation of words with and without sentence structure showed structural facilitation in a reaction-time search task for specified items.

Other studies have used word-like items. Salzinger \& Eckerman (1967) used serial presentation at a rate of $1 \mathrm{sec} / \mathrm{item}$.
Structural facilitation was suppressed only in declarative, not at all in passive, negative interrogative strings. O'Connell, Turner, \& Onuska (1968) used oral presentation, which is, of necessity, serial. Structural facilitation was found in intonated (but not in monotone) strings, despite the serial mode of presentation. Finally, O'Connell, Stubbs, \& Theby (1968) used two rates of presentation, 1 and $3 \mathrm{sec} / \mathrm{item}$, and the same materials with which Bryk \& O'Connell (1967) had already found structural facilitation with whole presentation. The same pattern of structural facilitation was found with serial presentation as had been found with whole presentation. The effect was due, however, to the addition of morphology; the condition with both morphological and syntactic structure did not add a significant amount to the facilitation. The slower rate of presentation led to better learning without suppressing structural facilitation.

A replication and extension of O'Connell, Turner, \& Onuska (1968) by O'Connell (in press), with native speakers of German, disclosed facilitation in intonated strings at the high structure level (morphology and syntax). In strings of actual lexical items (German or English), the relative facilitative influence of intonation and structure depended on the redundance of the linguistic cues.

Without adverting to Epstein's (1962) research, Jensen \& Rohwer (1965, p. 602) had concluded that serial learning "is relatively unaffected by the amount of previous verbal experience." In a subsequent study (Levin \& Rohwer, 1968, p. 186), Ss learned a 14-item serial list "in either the traditional manner, or with the aid of individual phrases, or in the context of a single sentence." Contrary to the earlier conclusion, it was found that the sentence condition led to better performance than did any of the other conditions.

Without specifying them, Epstein acknowledged that there were many differences between the 1961 experiment and the serial-anticipation one. It is worth noting that the response to graphemic stimuli was phonemic, that it too was serialized, and that it was interjected between discrete stimulus items. Salzinger \& Eckerman (1967) and O'Connell, Stubbs, \& Theby (1968) have called attention to these differences. Many of the commentators on this research, however, have noted only the serial presentation and have concluded that the change in stimulus conditions was responsible for the suppression of syntactic facilitation as an experimental effect (Osgood, 1963, p. 282; Rosenberg, 1965, p. 127; Forster, 1966, p. 293; Hörmann, 1967, p. 252; Neisser, 1967, p. 263; Dunne, 1968, p. 462; Osgood, 1968, p. 514). Epstein himself was somewhat more cautious. Osgood (1963, p. 282) has also suggested that, since $2 \mathrm{sec} /$ item was slower than the normal rate for reading, Ss reacted to the series as unrelated items, so that sequential syntactic habits were largely obliterated.

The currently available literature yields a confusing picture of the influence of linguistic structure in nonsense strings with serial presentation. An effort at replicating the effect in the German language was therefore thought worthwhile. A German-language study also affords an opportunity to isolate total viewing time and total processing time per string per trial. Hence, presentation rates that bracketed those of the O'Connell, Stubbs, \& Theby (1968) study were selected: 2 and $4 \mathrm{sec} / \mathrm{item}$. It was hypothesized that, as in the previous study, the longer visual time would lead to better learning. Structural facilitation was expected to appear in all the time conditions and to be due primarily to the addition of morphology rather than to the addition of syntax.

\section{STIMULI}

The structural conditions selected for the experiment were: no structure $(\mathrm{N})$, presence of morphology and functors (L), and presence of morphology, functors, and syntactic order $(\mathrm{H})$. In all strings, the same graphemes appeared, and item length and number of syllables per item were held constant. Each word-like item was typed in upper-case letters on a separate $10 \times 15$ file card. The actual strings used were the following:

\section{N-PED PEFUP NEI IED DEKLEIN MOT HIB NEHI TEKÖ ESRON \\ L-PED MOT HIB EIN FUPPE DIE HÖTE RONSE KINE KLEINDE \\ H-EIN RONSE PED MOT HIB FUPPE DIE KINE HÖTE KLEINDE}

\section{SUBJECTS}

The Ss were 63 men and women, students at the Psychological Institute of the Free University of Berlin. Volunteers were assigned randomly to experimental groups in a 3 by 3 (structure by rate of presentation) factorial design and run individually.

\section{PROCEDURE}

All Ss received instructions to learn the entire string in the correct order. The presentation and timing procedure was 
planned in the following manner: Each $S$ received a set of 10 cards with an item on each and with a cover card marked $A N F A N G$. A set of cards with dummy items was also used during instructions to familiarize Ss with the procedure. A timing device was used that produced both a click sound and a flash of green light from a panel lamp every $2 \mathrm{sec}$. The Ss were instructed to turn a card every $2 \mathrm{sec}$ in rhythm with the signals. The three timing conditions were as follows: In the first condition $(2 /-)$, Ss viewed 10 cards in succession; in the second $(2 / 0)$, a blank card succeeded each of the 10 for $2 \mathrm{sec}$; in the third $(2 / 2)$, the identical item was presented twice in succession instead of the blank card. In the former two conditions, therefore, visual time was identical; in the latter two, total available time was identical.

After each trial $(20$ or $40 \mathrm{sec})$, the signals were stopped, and the $S$ wrote the items on a slip of paper that had 10 dashes dittographed on it for the respective items. The Ss did not have available what they had written on previous trials. The response interval was essentially unpaced, but the $E$ went on to the next trial as soon as it was clear that the $\mathrm{S}$ had written all he could. Thus, Ss were not allowed to study what they had written. Trials were continued until two correct reproductions had been made, i.e., all items correctly spelled and in the correct order.

\section{RESULTS}

A number of response measures were inspected and found to reflect the same

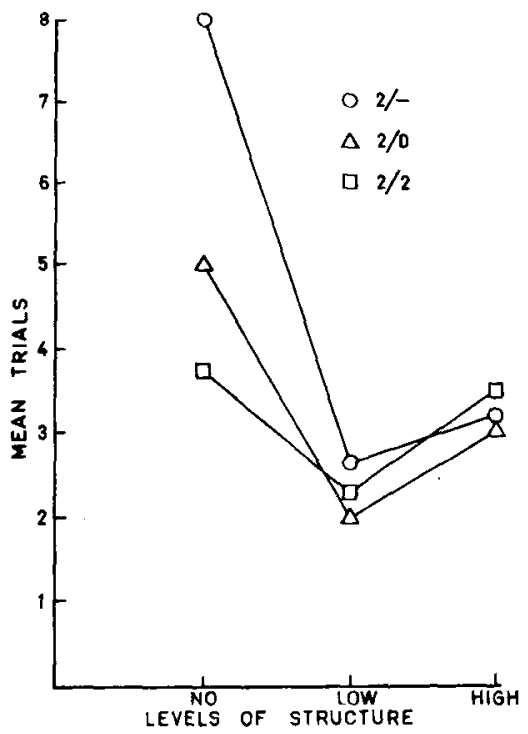

Fig. 1. Mean trials to consistently correct recall across all items. See text for explanation of timing conditions: $2 /-, 2 / 0$, and $2 / 2$. pattern of results: trials to a criterion of 1 and 2 correct trials, perseverative, nonperseverative, and combined errors. These responses are, however, based on less data and are relatively less sensitive than mean trials to consistently correct recall across all items and mean number of items correct in the first five trials. The latter two response measures were therefore selected for the analyses of variance. In both analyses, the structural factor was significant: $F=14.07, \mathrm{df}=2 / 54, p<.005$, and $F=15.55, \quad d f=2 / 54, \quad p<.005$, respectively. No other factors were significant. Multiple comparisons showed Conditions $\mathrm{L}$ and $\mathrm{H}$ different from $\mathrm{N}$ but not from one another. These results are shown for the respective response measures in Figs. 1 and 2.

Estimates of the word-like quality of the items (based on an additional $12 \mathrm{Ss}$ ) were correlated with number of errors per item in the three structural conditions: for Condition $\mathrm{N}, \rho=-.64(\mathrm{p}<.05)$; for $\mathrm{L}$, $\rho=-.55(.10>\mathrm{p}>.05)$; for $\mathrm{H}, \rho=-.62$ $(\mathrm{p}<.05)$. Similar one-tailed tests were found short of significance when the same estimates were correlated with trials to criterion for the individual items and with the number of postexperimental German words associated with the items. Various comparisons of the number and type of word associations made to the items across conditions disclosed no systematic variations.

\section{DISCUSSION}

The experiment yields clear evidence of structural facilitation. The effect is to be

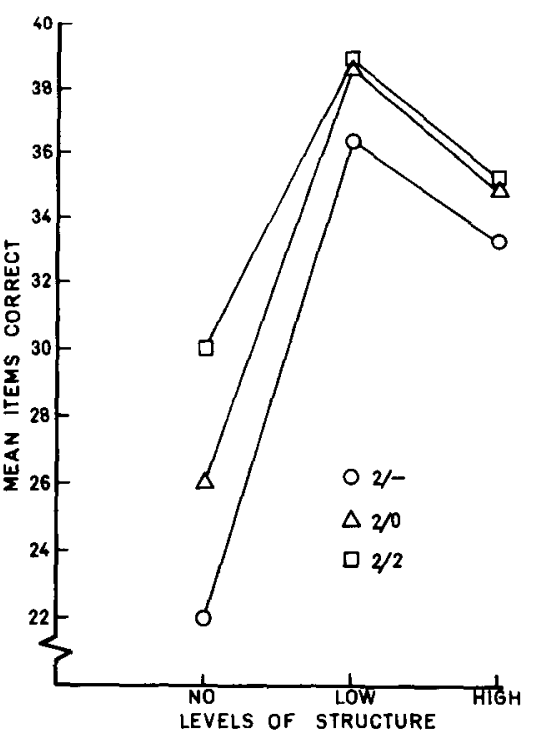

Fig. 2. Mean number of items correct in the first five trials. See text for explanation of timing conditions: $2 /-, 2 / 0,2 / 2$.
Table 1

Recognition of Linguistic or Rote Structure by Ss in Structure Conditions $N, L$, and $H$

\begin{tabular}{ccrr} 
& \multicolumn{2}{c}{ Recognition of Structure } \\
Structure & Linguistic & Rote & Total \\
\hline N & 3 & 3 & 6 \\
L & 6 & 10 & 16 \\
H & 8 & 3 & 11 \\
\hline
\end{tabular}

localized, however, at the morphological level. The $L$ and $H$ structural conditions have in common the presence of functors and bound morphemes. The additional presence of syntactic order of items in Condition $\mathrm{H}$ seems to have added no facilitative effect. This outcome can hardly be considered a suppression of syntactic facilitation ascribable to serial presentation of the items. Were this the case, the longer viewing and/or processing time should have shown significantly less facilitation, or at least some differential effect. In addition, the fact that the pattern of facilitation is the same as that found by Bryk \& O'Connell (1967), with similar materials in the English language and whole presentation, argues against the "suppression" interpretation. The pattern is, of course, also the same as that found by O'Connell, Stubbs, \& Theby (1968) with overlapping item/second intervals. Indeed, even were the time differences (which are largest, and therefore suggestive of some real effect, in Condition $N$ ) significant, a more logical interpretation would suggest itself: With more viewing and/or processing time, facilitation is simply not needed. In other words, linguistic or other forms of organization are utilized by $\mathrm{Ss}$ in economical fashion and as needed. Evidence to this effect has been found recently by Bryk (1968): Linguistic structure is utilized less in short strings than in longer ones for purposes of memory and/or processing. Only when a strain is put on the processing capacity of Ss does dramatic structural facilitation appear.

In this same vein, it is possible that $\mathrm{Ss}$ in the present experiment found a form of subjective organization in Condition $L$ that was more salient and hence more economical than the linguistic structure-or at least complementary to it. The sequence of one- and two-syllable items in Condition $\mathrm{L}$ was as follows: 1111212222. A postexperimental interview disclosed a recognition of structure roughly approximating the facilitative effects found in the experiment. Recognition of linguistic structure (e.g., "Pseudosatz") and rote structure (e.g., 1111212222 ) for the levels of structure are shown in Table 1.

The experiment clearly supports the existence of linguistic structural facilitation 
in the learning of serially presented nonsense strings in the German language. But it suggests, as well, that time and nonlinguistic structure (through subjective organizational schemes of various kinds) can be traded off for linguistic structure on the basis of economy, efficiency, or need.

\section{REFERENCES}

BRYK, J. A. The influence of syntax in rote verbal learning. Unpublished doctoral dissertation, St. Louis University, 1968.

BRYK, J. A., \& O'CONNELL, D. C. Immediate recall as a function of grammatical structure and mode of presentation. Psychonomic Science, 1967, 8, 437-438.

DENNER, B. Perceptual processing of syntactically structured and unstructured strings. Perceptual \& Motor Skills, 1966, 23, 1310.

DUNNE, M. M. The effect of syntactic structure on learning. Journal of Verbal Learning \& Verbal Behavior, 1968, 7, 458-463.

EPSTEIN, W. The influence of syntactical structure on learning. American Journal of Psychology, 1961, 74, 80-85.

EPSTEIN, W. A further study of the influence of syntactical structure on learning. American Joumal of Psychology, 1962, 75, 121-126.

EPSTEIN, W., \& ARLINSKY, M. The interaction of syntactical structure and learning instructions. Psychonomic Science, 1965, 3, 59-60.

FORSTER, K. I. The effect of syntactic structure on nonordered recalt. Journal of Verbal Learning \& Verbal Behavior, 1966, 5, 292-297.

HÖRMANN, H. Psychologie der Sprache. Berlin: Springer-Verlag, 1967.

JENSEN, A. R., \& ROHWER, JR., W. D. Syntactical mediation of serial and paired-associate learning as a function of age. Child Development, 1965, 36, 601-608.

LEVIN, J. R., \& ROHWER, JR., W. D. Verbal organization and the facilitation of serial learning. Journal of Educational Psychology, $1968,59,186-190$.

NEISSER, U. Cognitive psychology. New York: Appleton-Century-Crofts, 1967.

O'CONNELL, D. C. Nonsense strings, words, and sentences: Some cross-linguistic comparisons. Psychologische Forschung, in press.

O'CONNEIL, D. C., STUBBS, C. L., \& THEBY, M. A. Facilitation of recall by structure in serially presented nonsense strings. Psychonomic Science, 1968, 12, 263-264.

O'CONNELL, D. C. TURNER, E. A., \& ONUSKA, L. A. Intonation, grammatical structure, and contextual association in immediate recall. Journal of Verbal Learning \& Verbal Behavior, 1968, 7, 110-116.

OSGOOD, C. E. Psycholinguistics. In S. Koch (Ed.), Psychology: A study of a science. Vol. 4. New York: McGraw-Hill, 1963. Pp. 244-316.

OSGOOD, C. E. Toward a wedding of insufficiences. In T. R. Dixon \& D. L. Horton (Eds.), Verbal behavior and general behavior theory. Englewood Cliffs, N. J Prentice-Hall, 1968. Pp. 495-518.

ROSENBERG, $S$. The influence of grammatical and associative habits on verbal learning. $\ln S$. Rosenberg (Ed.), Directions in psycholinguistics. New York: Macmillan, 1965. Pp. 121-145.

SALZINGER, K., \& ECKERMAN. C. Grammar and the recall of chains of verbal responses. Journal of Verbal Learning \& Verbal Behavior.
$1967,6,232-239$.

SIMPSON, W. E. Effects of approximation to sentence word-order and grammatical class upon the serial learning of word lists. Joumal of Verbal Learning \& Verbal Behavior, 1965 4, $510-514$.

WALES, R. J. Problems of repetition in verbal learning. Paper at the British Psychological Society, London, England, 1964.
NOTE

1. The research reported in the following article has been supported by the Alexander von Humboldt lioundation of Bad Godesberg, Germany, and by the Psychological Institute of the Free University of Berlin. It was made possible by the generosity of St. Louis University in granting the first author a leave of absence for purposes of research.

\section{Choice reaction time as a function of intersensory anticipation}

\section{CAROLYN DONALDSON and ALFRED E. HALL, 1 College of Wooster, Wooster, Ohio 44691}

Choice $R T$ of 10 college students was compared under two conditions. One condition was a single-choice condition in which, I sec after a warning signal, one of a pair of stimulus lights was flashed and $S$ was required to move a right-hand lever in the appropriate direction. In the double-choice condition, a second stimulus (high or low tone) followed the first stimulus by $1 / 2 \mathrm{sec}$, and $S$ was, in addition, required to respond to it by moving a left-hand lever in the appropriate direction. Average $R T$ to the light in the single-choice condition was significantly shorter $(p<.01)$ than the RT to the same stimulus in the double condition. These data provide additional evidence that present behavior is affected by S's expectation of the immediate future.

The effect of anticipation upon reaction time (RT) has been the object of several studies. Poulton (1950) found that simple RT was about $25 \mathrm{msec}$ longer when the $S$ was required to initiate a complex pattern-tracing task than when he had to make a simple response (break an electrical contact). Poulton interpreted these and other findings to mean that present performance is affected by the S's awareness of future events or requirements. Inhibition of simple RT was also found in a study by Helson \& Steger (1962), in which Ss were required to respond to a stimulus light that was itself followed 10 to $180 \mathrm{msec}$ later, on half the trials, by another stimulus light. However, other experiments (Lappin \& Eriksen, 1964 Koplin, Fox, \& Dozier, 1966) have failed to replicate this increase in simple RT.

Gottsdanker, Broadbent, \& Van Sant (1963) found inhibition of RT to occur in a choice-RT situation. They measured choice RT for six adults under two conditions. One was a single-choice condition in which a warning light flashed, and $1 \mathrm{sec}$ later, one of two previously designated lights flashed. The $S$ responded by moving a lever in the direction of the signal light that flashed. The other condition was a double-choice situation that was like the above condition, except that $1 / 2$ sec after the first stimulus lamp was presented, one of another pair of stimulus lamps was flashed. The results showed that, for all Ss, the mean RT for the single-choice condition was significantly shorter than was the same response in the double-choice condition.

The design of the present study was similar to that of Gottsdanker et al (1963), except that stimuli of different modalities were employed. The main purpose of the experiment was to study the effects of a second (auditory) stimulus on the RT to a first (visual) stimulus.

\section{SUBJECTS AND MATERIALS}

The Ss used were 10 undergraduate, introductory psychology students at the College of Wooster ( 5 male and 5 female). Five additional students served as pilot Ss. All Ss were right-handed.

The visual stimuli were two yellow $1 / 4-W$ bulbs. The auditory stimuli were two easily discriminable tones: one approximately $300 \mathrm{~Hz}$ and the other about $800 \mathrm{~Hz}$.

The display and controls consisted of a $3 \times 2 \frac{1}{2} \mathrm{ft}$ flat-black board. It was supported on a table at the longer ends by two 2 in. $x 4$ in. $x 3 \mathrm{ft}$ wooden blocks. In the center of the board were four $1 / 4-W$ bulbs placed in a 1 -in. square. Centered and $1 / 2$ in. above these was another $1 / 4-\mathrm{W}$ bulb (white) used as the warning light. Three inches above this bulb was a $4 \times 4 \times 4$ in. metal speaker that presented the two tones. The pair of stimulus bulbs on the right side of the center display was yellow, and that on the left was red. (The latter pair was not used in this experìment.) Centered between the two lamps on the right and 1 in. farther to the right was a 